\title{
A distribuição geográfica da forma pronominal a gente na fala do português europeu
}

\author{
Geographic distribution of the pronominal form a gente in European Portuguese \\ speech
}

\author{
Gislaine Aparecida de Carvalho ${ }^{1}$ \\ Universidade do Estado de Mato Grosso \\ Géssica Cristina Carvalho Corrêa ${ }^{2}$ \\ Universidade do Estado de Mato Grosso
}

\begin{abstract}
- RESUMO: Este artigo mostra que a reestruturação no paradigma pronominal com a inserção de "a gente" no quadro de pronomes pessoais já não pode mais ser apontada como uma das diferenças sintáticas que distanciam o português europeu do português brasileiro. Para apresentar a distribuição geográfica da forma pronominal "a gente" no território continental português, as pesquisas seguiram os ritos da Sociolinguística Variacionista e mapearam em amostras de fala - entrevistas da coletânea do CORDIAL-SIN - a frequência de uso dessa expressão pronominal com o objetivo de verificar sua produtividade. Os resultados além de confirmar a consolidação dessa forma "inovadora", mostraram que o cânone pronome "nós" é pouco produtivo, especialmente na sua forma plena.

- PALAVRAS-CHAVE: Português europeu; Variação linguística; Distribuição geográfica; Forma pronominal "a gente".

- ABSTRACT: Restructuration of pronominal paradigm by the insertion of "a gente" in the framework of pronominal pronouns cannot be appointed as one of the syntactic differences that puts apart European and Brazilian Portuguese is shown by this paper. In search of presenting the geographical distribution of the pronominal form "a gente" in the Portuguese continental territory researches adopted the Sociolinguistic rites and mapped in speech - on the interviews of CORDIAL-SIN collection - the use of this expression aiming to verify its frequency. More than confirm the consolidation of this "innovative" form, results show that the canonical pronoun "nós" is not that productive, especially in its overt form.
\end{abstract}

- KEYWORDS: European Portuguese; Linguistic variation; Geographic distribution; Pronominal form "a gente"

\section{Introdução}

A reorganização do sistema pronominal no português brasileiro traz para essa língua características que a distanciam da variedade europeia: tendência ao preenchimento do sujeito pronominal, ao objeto nulo (possível em contextos distintos do português europeu), ao uso de pronome tônico na posição de objeto (e em sujeito de infinitiva), ao uso de relativas não-padrão, ao enfraquecimento da morfologia flexional e das relações de concordância, à perda da inversão livre, (estabelecimento de SV), além da reestruturação no paradigma pronominal com a inserção de "a gente" e "você"

\footnotetext{
1 Doutora em Linguística e Língua Portuguesa pela UNESP/Araraquara. Docente do Curso de Letras da UNEMAT/Alto Araguaia e do Programa de Pós-graduação em Linguística da UNEMAT/Cáceres. Vice-líder do Grupo de Pesquisa Variação e invariantes na linguagem. gislainemail26@yahoo.com.br

2 Mestre em linguística Programa de Pós-graduação em Linguística da UNEMAT/Cáceres. Docente em caráter temporário do Curso de Letras da UNEMAT/Alto Araguaia. gegeh 2006@hotmail.com
} 
no quadro de pronomes pessoais. (TARALLO (1993); DUARTE (1995), GALVES (2001))

A reorganização do sistema pronominal, apontada como uma das diferenças sintáticas entre as variedades brasileira e europeia do português, motivou a realização deste estudo, que buscou investigar em amostras de fala do território do português continental, como se realiza o pronome de primeira pessoa do plural, nessa língua, cuja classificação teórica de [+] pro-drop já não resiste às evidencias apresentadas por estudos - (Oliveira (2006), Carvalho (2009), Sória (2013)) - que mostraram não só o aumento no número de sujeitos pronominais (em contextos atípicos), mas também a consolidação do uso da forma pronominal "a gente", semelhantemente ao português brasileiro.

Para mapear a distribuição da forma pronominal "a gente" na fala do português europeu, recorremos a pesquisas, cuja base teórico-metodológica provém da Sociolinguística Variacionista (Weinreich, Labov, Herzog, 2006 (1968); Labov, 2008 (1972), 1994, 2001), para mostrar numérico e geograficamente a produtividade desse "novo" pronome.

O corpo deste artigo é composto por uma única seção, que está assim subdividida: em 1.1 a distribuição geográfica da forma pronominal "a gente" é mapeada por Carvalho (2009), pesquisa que analisou, em tempo aparente, amostras de fala de 10 localidades do território português, disponíveis no Corpus Dialetal para o Estudo da Sintaxe (CORDIAL-SIN). Na subseção 1.2, recorremos a Sória (2013) para mostrar a frequência de "a gente" (relativamente à de "nós" e à do sujeito nulo de $1^{\mathrm{a}}$ pessoa do plural) nos dialetos do português europeu (CORDIAL-SIN). A subseção 1.3 exibe os resultados da nossa pesquisa, no que se refere exclusivamente à primeira pessoa do plural (nós x a gente), atendendo ao propósito desta apresentação.

\section{A distribuição geográfica da forma pronominal a gente na fala do português europeu}

\subsection{O estudo de Carvalho}

Para mapear a distribuição geográfica da forma pronominal "a gente" em posição de sujeito (preenchido ou nulo), Carvalho (2009) analisou, em tempo aparente, amostras de fala de 10 localidades do território português, disponíveis no Corpus Dialetal para o Estudo da Sintaxe (CORDIAL-SIN).

Reproduz-se o mapa 1 (retirado de Carvalho, 2009), no qual estão sinalizados e nomeados os locais da investigação.

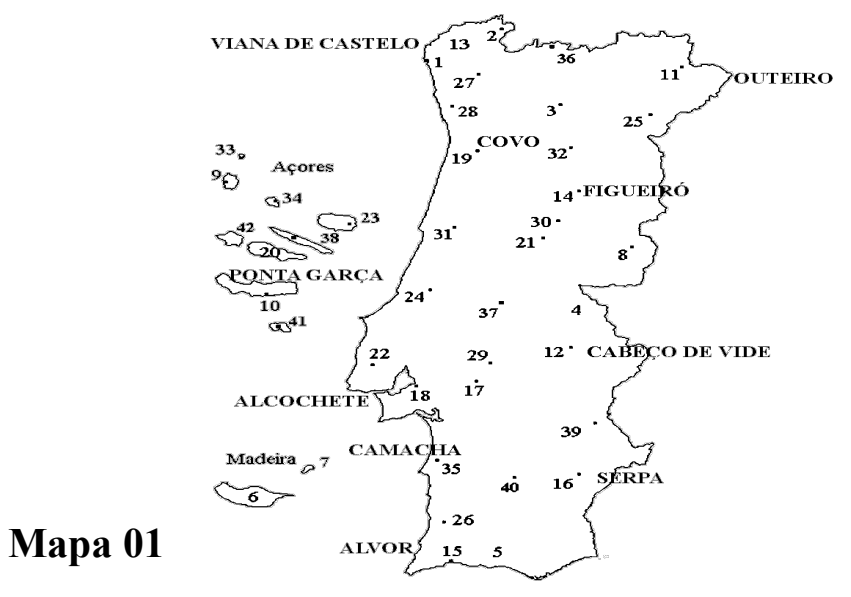


Envolto por dogmas, a forma pronominal "a gente" não é mencionada na grande maioria dos compêndios gramaticais de cunho normativista, quer no português europeu, quer no português brasileiro. Reportemo-nos ao texto de Pereira, pesquisadora portuguesa, para mostrar as restrições de uso prescritas para essa expressão:

Outras gramáticas quer antigas, como a Grammatica Philosophica da Língua Portugueza de Soares Barbosa (1822) e Gramática da Língua Portuguesa de João de Barros, quer recentes, como a Gramática da Língua Portuguesa de Mateus et al. (1983) não dão qualquer espaço a esta expressão. Note-se que, até há pouco tempo atrás, também nas escolas se censurava o uso de a gente, a coberto da perspectiva normativa banalizada no bordão que "agente é da polícia". Estes factos revelam que não só no meio escolar, mas também no meio académico, este pronome não era encarado como parte da gramática do português padrão, mas talvez como uma particularidade da língua familiar oral, como alguns estudiosos chegam a referir. (PEREIRA, 2003, p.13)

Se, por um lado, a forma pronominal "a gente" ainda não é mencionada na grande maioria dos compêndios gramaticais de cunho normativista; por outro lado, no uso da língua, essa expressão pronominal já é uma realidade também no português europeu.

Vejamos o resultado da investigação feita por Carvalho (2009):

Tabela 1 - Quantificação e porcentagem de ocorrências do cruzamento entre localidade e sujeito "a gente" preenchido e nulo.

\begin{tabular}{lcccc}
\hline \multicolumn{1}{c|}{ Localidade } & Sujeito preenchido & Sujeito nulo & Total \\
\hline Alcochete (Distrito de Setúbal) & $61(85 \%)$ & $11(15 \%)$ & 72 \\
Alvor (Distrito de Faro) & $120(93 \%)$ & $09(7 \%)$ & 129 \\
Cabeço de Vide (Distrito de Portalegre) & $20(77 \%)$ & $06(23 \%)$ & 26 \\
Camacha (Distrito de Funchal) & $87(93 \%)$ & $07(7 \%)$ & 94 \\
Ponta Garça (Distrito de Ponta Delgada) & $317(90 \%)$ & $37(10 \%)$ & 354 \\
Serpa (Distrito de Beja) & $129(77 \%)$ & $38(23 \%)$ & 167 \\
Arcos (Distrito de Viana de Castelo) & $51(75 \%)$ & $17(25 \%)$ & 68 \\
Outeiro (Distrito de Bragança) & $64(68 \%)$ & $30(32 \%)$ & 94 \\
Figueiró(Distrito de Guarda) & $33(90 \%)$ & $04(10 \%)$ & 37 \\
Covo (Distrito de Aveiro) & $78(84 \%)$ & $15(16 \%)$ & 93 \\
\hline \multicolumn{2}{c}{ Total } & 960 & 174 & 1134 \\
\hline Adaptado de Carvalho (2009) & \multicolumn{3}{|c}{}
\end{tabular}

A Tabela 1 (adaptada de Carvalho 2009) mostra que a forma "inovadora" está presente em todas as localidades e, quando comparada à primeira pessoa do plural "nós", a pesquisa revelou números surpreendentes: a frequência de uso da forma "inovadora" (a gente) é superior à do cânone pronome (nós).

A tabela 2, exibe a comparação entre "nós" e "a gente".

Tabela 2 - Quantificação e porcentagem de ocorrências de "nós" X "a gente" sujeito preenchido e nulo.

\begin{tabular}{cccc}
\hline Pessoa gramatical & Sujeito preenchido & Sujeito nulo & Total \\
\hline Nós & $92(65 \%)$ & $49(35 \%)$ & 141 \\
A gente & $960(85 \%)$ & $174(15 \%)$ & 1134 \\
\hline Total & 1052 & 223 & 1275 \\
\hline Adaptado de Carvalho (2009) & & &
\end{tabular}


Em números percentuais, a forma "inovadora" totaliza $89 \%$ do total de ocorrências de primeira pessoa do plural; para o pronome "nós", o índice foi de 11\%. A diferença entre este e aquele é flagrante (78\%).

\subsection{O estudo de Sória}

A realização do sujeito de primeira pessoa do plural no português europeu também foi investigada por Sória (2013). Dentre outras questões, a pesquisadora analisou:

a) a distribuição geográfica de "a gente" e de "nós" no território continental português (CORDIAL-SIN);

b) a frequência de "a gente" (relativamente à de "nós" e à do sujeito nulo de $1^{\text {a }}$ pessoa do plural) nos dialetos do português europeu (CORDIAL-SIN).

Com relação à distribuição geográfica de "a gente", os resultados das análises quantitativas mostraram a consolidação dessa forma pronominal, em todas as localidades investigadas.

Na reprodução do mapa 2 - (retirado de Sória (2013)) - estão sinalizados com pontos pretos, todas as localidades de Portugal em que a forma "a gente" é realizada com valor pronominal (seja como substituto de nós, como sujeito indeterminado, complemento direto, complemento indireto, pronome possessivo, oblíquo, etc.).

A presença de "a gente" no território português continental ${ }^{3}$ :

\section{Mapa 02}

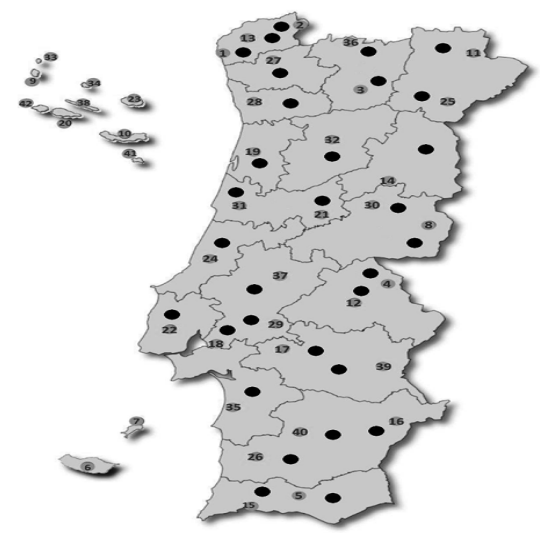

\footnotetext{
${ }^{3}$ As localidades relativas às ilhas portuguesas não foram estudadas, quais sejam: as identificadas com os números 6, 7, 9, 10, 20, 23, 33, 34, 38, 41 e 42, relativas a Câmara de Lobos, Caniçal (Funchal), Camacha, Tanque (Funchal), Fajãzinha (Horta), Ponta Garça (Ponta Delgada), Bandeiras, Cais do Pico (Horta), Fontinhas (Angra-do-Heroísmo), Corvo (Horta), Graciosa (Angra do Heroísmo), Calheta (Angra do Heroísmo), Santo Espírito (Ponta Delgada) e Cedros (Horta), respectivamente. (SÓRIA, 2013)
} 


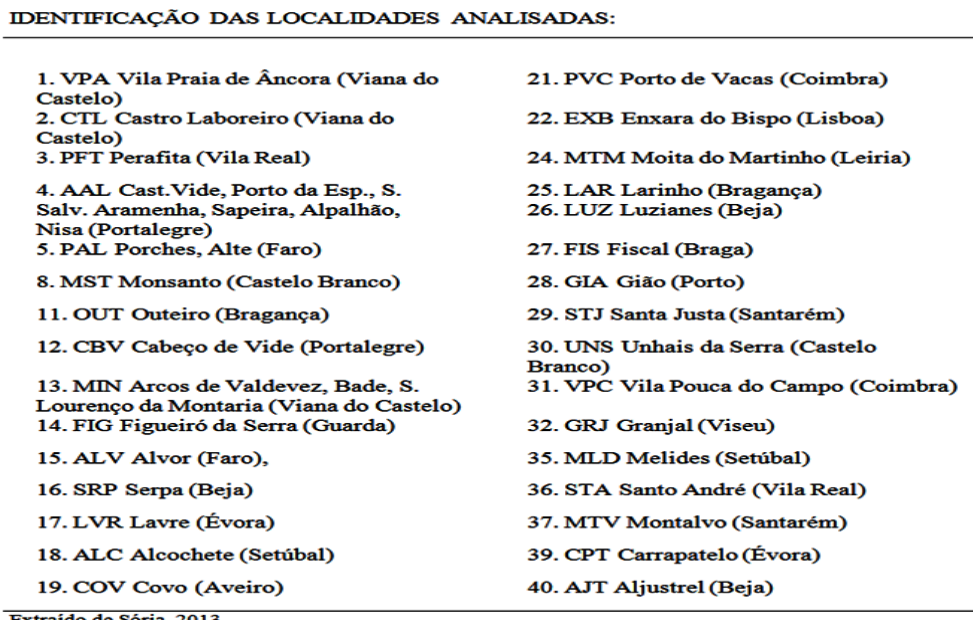

Relativamente à primeira pessoa do plural "nós", o estudo de Sória (2013) mostrou que a distribuição não é uniforme em todas as localidades do português continental - corpus do CORDIAL-SIN. Em Cabeço de Vide e Alcochete não se registrou nenhuma ocorrência do cânone pronome, independentemente da função sintática.

Geograficamente, a presença de "nós" no território português continental (de acordo com os dados do corpus CORDIAL-SIN) está assim configurada:

\section{Mapa 03}

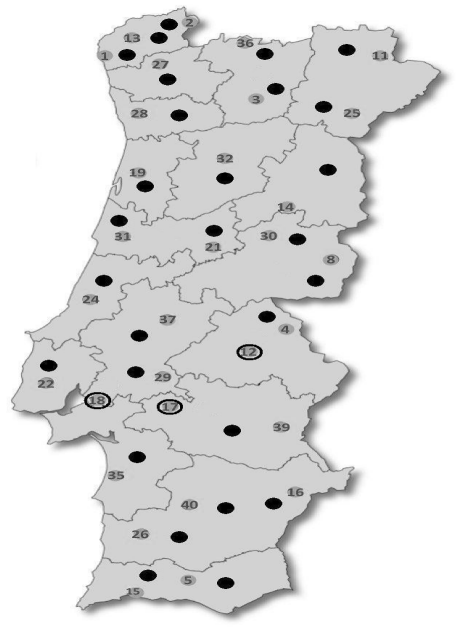

Quando se observa a realização do pronome "nós", exercendo a função sintática de sujeito, Lavre, em Évora - (localidade 17) - também não consta do mapa: a única ocorrência, registrada em estrutura não canônica, desempenha a função de pronome possessivo:

(1) "INQ1 Olhe, e o pequenino?

INF: Ou os chaparrais - já não há quem diga... Isto é a linguagem de nós"4.

Ao comparar a FREQUÊNCIA DE "NÓS" E "A GENTE", os dados revelaram ser a última mais produtiva que a primeira, totalizando 2613 ocorrências de

\footnotetext{
${ }^{4}$ Exemplo retirado de Sória (2013)
} 
sujeitos preenchidos. Em números percentuais, Sória (2013) registrou 81\% de sujeitos preenchidos pela forma pronominal "a gente" contra $11 \%$ de sujeitos realizados pelo pronome "nós".

Quando se observam as localidades, o preenchimento da casa do sujeito pela forma "inovadora"5 "a gente" é majoritário em 92\% dos locais de investigação. O uso dessa forma pronominal só é superado pelo pronome "nós" em VILA PRAIA DE ÂNCORA (1), CASTRO LABOREIRO (2) 6 e SANTO ANDRÉ (36) 7 . Porém, se se observam os índices percentuais, em SANTO ANDRÉ (36), a diferença de uso de "a gente" x "nós" é inexpressiva $(49,2 \%)$ e $(50,8 \%)$, respectivamente.

\subsection{O nosso estudo}

Teorias que postulam diferenças sintáticas entre o português brasileiro e o português europeu motivaram o nosso desejo em buscar evidências quantitativas, que pudessem avaliar 'quão pro-drop' é a variedade de além-mar. Para isso, recorremos à Sociolinguística Variacionista, de linha laboviana. Os dados de análise foram submetidos ao Pacote Computacional GOLDVARB, ferramenta que, além oferecer os resultados em porcentagem - cuja frequência pode estar enviesada - permite a regressão logística (peso relativo) com o cálculo de desvio da média ponderada de todas as inter-relações existentes dos grupos de fatores na atuação da regra variável.

Para a composição do corpus, recorremos ao CORDIAL-SIN", que é uma coletânea de entrevistas selecionadas no âmbito dos seguintes projetos: ALEPG (Atlas Linguístico e Etnográfico de Portugal e da Galiza); ALLP (Atlas Linguístico e Etnográfico dos Açores) e BA (Fronteira Dialetal do Barlavento Algarvio). Os textos, transcritos da modalidade oral, foram produzidos por idosos nativos portugueses que sempre viveram na zona rural, com pouca instrução. Das 42 localidades do território continental de Portugal e dos arquipélagos da Madeira e dos Açores, selecionamos três entrevistas da região central de Portugal: Moita do Martinho (Leiria), Figueiró da Serra (Guarda) e Vila Pouca do Campo (Coimbra).

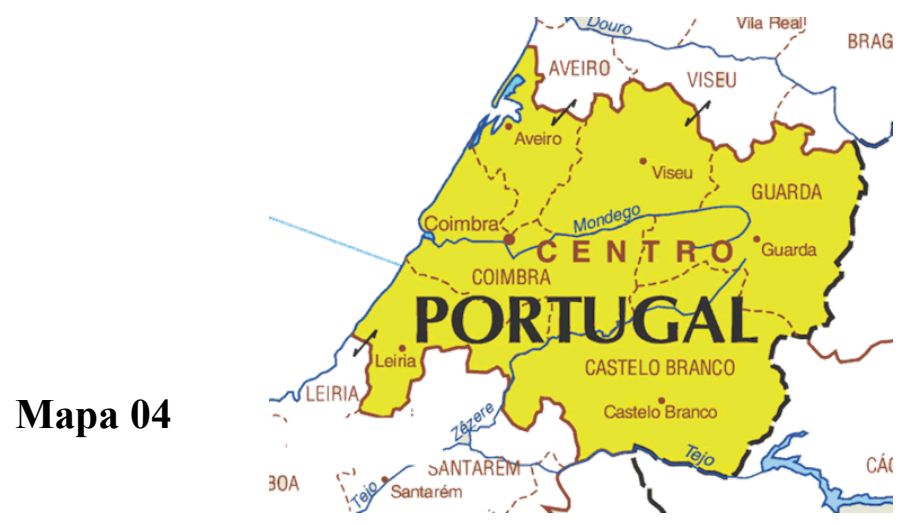

Formularmos a hipótese de que "a tradicional classificação do português europeu como língua [+] pro-drop ainda se manteria parcialmente, sendo o sujeito nulo

\footnotetext{
5 Chamamos "a gente" de forma inovadora, uma vez que, a sua inserção no quadro de pronomes pessoais ainda não é unânime dentre os estudiosos.

${ }^{6}$ Vila Praia de Âncora e Castro Laboreiro, ambas em Viana do Castelo - (Ver mapa 2).

${ }^{7}$ Santo André, em Vila Real - (Ver mapa 2).

${ }^{8}$ Corpus Dialetal para o Estudo da Sintaxe disponibilizado pela Internet no endereço: $<$ http://www.clul.ul.pt/sectores/variacao/cordialsin/projecto_cordialsin.php $>$.
} 
majoritário em contextos em que o preenchimento não é regra categórica, exceto com a forma pronominal "a gente", que além de liderar o número de sujeitos foneticamente realizados, ainda exibiria variação na concordância número-pessoal.

Para atender ao objetivo deste artigo, faremos um recorte, visando exclusivamente a distribuição geográfica da forma pronominal "a gente", cujo resultado pode ser visto na Tabela 3 .

Tabela 3 - Quantificação e porcentagem de ocorrências da forma pronominal "a gente" nas localidades investigadas.

\begin{tabular}{ccccc}
\hline \multicolumn{5}{c}{ Localidade } \\
\hline Pessoa gramatical & Leiria & Coimbra & Guarda & Total \\
A gente & $45(17 \%)$ & $138(52 \%)$ & $82(31 \%)$ & 265 \\
\hline Total & 45 & 138 & 82 & 265 \\
\hline Adaptado de Corrêa (2017) & & &
\end{tabular}

Os números mostram que Coimbra concentra o maior percentual da forma "inovadora", (52\%). Apesar de a diferença entre Coimbra e Leiria ser de 35\%, as três localidades investigadas registram ocorrências com essa forma pronominal, confirmando, assim, sua consolidação no território continental português.

Além de estar presente em todas as localidades, a forma pronominal "a gente" responde por $25 \%$ do total geral de ocorrências. Percentual que se torna ainda mais expressivo se a compararmos à primeira pessoa do plural canônica "nós", cuja frequência é de 3\%. Em números, foram analisados 1050 dados, dos quais 265 são com a forma pronominal "a gente" e 30 são com o clássico pronome "nós".

Diferentemente do pronome nominativo "nós" que é afetado positivamente por sua forma nula; na expressão pronominal "a gente" o preenchimento se sobrepõe à categoria vazia. Vejamos os números obtidos na análise dos dados: "nós" $60 \%$ de sujeitos nulos x 40\% de pronome realizado; "a gente" 45\% de apagamento x 55\% de preenchimento.

\section{Considerações finais}

Embora a reestruturação no paradigma pronominal com a inserção de "a gente" no quadro de pronomes pessoais seja apontada como uma das diferenças sintáticas que distanciam o português europeu do português brasileiro, os resultados das pesquisas revelaram que na variedade de além-mar a forma pronominal "a gente" também já está consolidada.

Além de a expressão pronominal "a gente" ser muito produtiva, está, geograficamente, presente em todas as localidades investigadas. E, quando a comparamos ao clássico pronome "nós", verificamos diferentes comportamentos: a forma "inovadora é afetada positivamente pelo preenchimento; já para o cânone pronome, a preferência recai sobre a categoria vazia. A variação de uso da primeira pessoa do plural - nós e a gente - confirma, para o português europeu, sua reestruturação no paradigma pronominal, semelhantemente ao português brasileiro. Ousamos afirmar ainda que o apagamento do clássico pronome (nós) está intimamente associado à morfologia distintiva, ainda forte nessa variedade de língua; diferentemente da forma "inovadora", que por apresentar o verbo ora na $3^{\mathrm{a}}$ pessoa do singular, ora na $1^{\mathrm{a}}$ pessoa 
do plural e ora, ainda, na $3^{\mathrm{a}}$ pessoa do plural, apresenta alto índice de preenchimento. Tangencialmente a morfologia distintiva afeta o uso do pronome.

\section{REFERÊNCIAS}

CARVAlHO, G. A. de. A realização do sujeito no português europeu. 2009. 259 f. Tese (Doutorado em Linguística e Língua Portuguesa) - Universidade Estadual Paulista. Araraquara, 2009.

CORRÊA, G. C. C. A realização do sujeito na fala do centro de Portugal. (Dissertação de Mestrado em Linguística). 2017. 120 f. Universidade do Estado de Mato Grosso. Cáceres, 2017.

DUARTE, M. E. L. A perda do princípio "Evite pronome" no português brasileiro. Tese (Doutorado em Linguística). 149 f. Instituto de Estudos da Linguagem da Universidade Estadual de Campinas, Campinas, 1995.

DUARTE, M. E. L. Do pronome nulo ao pronome pleno: a trajetória do sujeito no português do Brasil. In: ROBERTS, I.; KATO, M. (orgs.) Português brasileiro: uma viagem diacrônica. Campinas: Editora da Unicamp, 1993, pp.107-128.

GALVES. C. C. A sintaxe do português brasileiro. In. GALVES. C. Ensaios sobre as gramáticas do português. Campinas, SP: Editora da Unicamp, 2001.

LABOV, W. Principles of Linguistic Change. Vol. 1: Internal Factors. Cambridge, MA/Oxford: Blackwell Publishers. 1994.

LABOV, W. Padrões Sociolinguísticos. São Paulo: Parábola Editorial, 2008 [1972].

OLIVEIRA, K. R. de. Nós, a gente e o clítico se como estratégias de indeterminação no português. (Dissertação de Mestrado em Linguística). 2006. 173 f. Universidade Federal de Uberlândia, Uberlândia, 2006.

PEREIRA, S. M de B. Gramática comparada de a gente: variação no português europeu. 2003. 149 f. Dissertação (Mestrado em Gramática Comparada) - Faculdade de Letras da Universidade de Lisboa, Universidade Nova de Lisboa, Lisboa, 2003.

SÓRIA, M. V. de P. Nós, a gente e o sujeito nulo de primeira pessoa do plural. (Dissertação de Mestrado em Linguística). 2013. 129 f. Faculdade de Letras da Universidade de Lisboa, Lisboa, 2013.

TARALLO, F. Relativization Strategies in Brazilian Portuguese. 1983. 273f. Tese (Doutorado em Filosofia. Área de concentração: Lingüística) - University of Pennsylvania, Pennsylvania,1983.

TARALLO, F. Sobre a alegada origem crioula do português brasileiro: mudanças sintáticas aleatórias. In: ROBERTS, I.; KATO, M. (orgs) Português brasileiro: uma viagem diacrônica. Campinas, Editora da Universidade Estadual de Campinas UNICAMP.

WEINREICH, U.; LABOV, W.; HERZOG M. Fundamentos empíricos para uma teoria da mudança linguística. São Paulo: Parábola Editorial, 2006 [1968].

Recebido em: janeiro de 2018. Aprovado em: abril de 2018.

Como citar este trabalho:

CARVAlHO, G. A. de; CORRÊA, G. C. C. A distribuição geográfica da forma pronominal a gente na fala do português europeu. Traços de linguagem, v. 2, n. 2, p. 44-51, 2018. 